\title{
DIATRIBES 12 E 13 DE MUSÔNIO RUFO: SOBRE COISAS RELATIVAS A AFRODITE E CASAMENTO
}

Aldo Dinucci ${ }^{1}$

Dedicado a Alfredo Julien

(recebido em 09/01/2013, aprovado em 10/04/2013)

Caio Musônio Rufo, estoico do primeiro século e mestre de Epicteto, era tirreno (etrusco), natural de Volsinii, na Etrúria ${ }^{2}$ e, segundo a Suda ${ }^{3}$, filho de um romano da classe equestre de nome Capito. Teria sido aluno de Hermógenes de Tarso ${ }^{4}$. Segundo as cronologias comumente aceitas 5 , nasceu no fim do reinado de Augusto ou no princípio do de Tibério (por volta do ano 30) e viveu até o reinado dos Flavianos (entre os anos 90 e 100)6.

Suidas menciona suas obras e as cartas supostamente trocadas entre Musônio e Apolônio de Tiana, consideradas espúrias 7 . Musônio nada escreveu, mas dois alunos seus incumbiram-se disso: Lucius (do qual nos chegaram 21 diatribes, preservadas por Estobeu ${ }^{8}$ ) e Pólio, cuja obra chegou-nos em fragmentos ${ }^{9}$.

Grande parte do que nos chegou sobre o pensamento de Musônio, como o dissemos, foi preservado por Estobeu, eclesiástico do século V, que organizou o material transmitido por Lucius

Doutor em Filosofia pela PUC/RJ e professor associado do Departamento de Filosofia da UFS. Coordenador do Grupo de Pesquisa em Filosofia Viva Vox (vivavox.site90.com). Membro permanente do Mestrado em Filosofia da UFS.

SUIDAS, Suda, M, 1305. Etrúria, chamada comumente de Tyrrhenia nos textos gregos e latinos: situava-se na região central da Itália, cobrindo parcialmente as áreas das atuais províncias italianas de Toscânia, Lácio, Emília Romana e Úmbria.

SUIDAS, Suda, M, 1305.

SUIDAS, Suda, E, 3046.

5

Cf. KING, 2011, p. 13.

Para uma biografia de Musônio, cf. nosso artigo: DINUCCI, A. Apresentação e Tradução dos Fragmentos Menores de Caio Musônio Rufo. IN: Trans/Form/Ação (UNESP. Marilia. Impresso), v. 35, p. 267, 2012. 
através de seleções. A edição crítica de Musônio é de autoria de Hense ${ }^{10}$, obra que deve ser complementada por um papiro incluído na edição de Lutz ${ }^{11}$. Tal edição crítica contém: 21 seleções longas (Diatribes), preservadas por Estobeu; 19 ditos, também preservados por Estobeu; 6 ditos nas Diatribes de Epicteto de Flávio Arriano; 2 ditos nas Moralia de Plutarco; 4 ditos nas Noites Áticas de Aulo Gélio (em latim); 1 dito em Aelius Aristides. A edição de Lutz acima mencionada é a primeira com tradução para o inglês. A segunda é aquela de Cynthia King ${ }^{12}$. Há ainda a edição de Jagu, com tradução em francês ${ }^{13}$.

Apresentamos aqui a tradução de duas diatribes: a 12 e a 13. A primeira trata de questões relativas ao sexo; a segunda, dividida em duas partes, porque assim organizada por Estobeu, trata do tema do casamento. Ambas tocam os temas sob o prisma do estoicismo romano.

\section{POR MUSÔNIO, DE "SOBRE COISAS RELATIVAS A AFRODITE"}

[12.01] Certamente não a menor parte da luxúria está nas coisas relativas a Afrodite, porque os luxuriosos precisam de variados entretenimentos, não apenas os legítimos, mas também os ilegítimos, não apenas com mulheres, mas também com homens; indo em busca às vezes de um amante, às vezes de outro, e não se satisfazendo com os que estão à mão, [12.05] mas desejando os que são difíceis de achar, buscando vergonhosas relações. Todas essas <coisas> são grandes acusações ao ser humano. É preciso, aos que não são luxuriosos ou não são maus, somente considerar justas as coisas relativas a Afrodite no casamento, e perpetradas para a geração de filhos, porque também são legítimas. [12.10] Mas < devem considerar> injustas e ilegítimas as coisas buscadas meramente por prazer, mesmo se forem no casamento. Das outras relações, as mais ilegítimas são as adúlteras, e,

10 HENSE. Musonii Rufi Reliquiae. Leipzig 1905. Outros trabalhos importantes e recentes que tratam de Musônio são: LAURENTI. Musonio, maestro di Epitteto. In: ANRW 2.36.3, 1989, p. 2105-2146; FRANCIS, J. A. Subversive virtue: asceticism and authority in the second-century pagan world. University Park, Pa., Pennsylvania State University Press. 1995, p. 11-16.

LUTZ, C. Musonius Rufus: The Roman Socrates. In: Yale Classical Studies, Volume X. A. R. Bellinger (Ed.). Yale: Yale University Press, 1947.

12 KING, C. Musonius Rufus: Lectures and Sayings. William B. Irvine (ed.). Seatle: CreateSpace, 2011.

13 JAGÚ, A. Musonius Rufus. Entretiens et Fragments. Inotrduction, Traductionet Commentaire. IN: Studien und Materialien zur Geschichte der Philosophie, Kleine Reine, Band I, Olms, 1979. 
dessas, nenhuma é mais intolerável que a de homens entre homens, porque é ato desavergonhado contra a natureza. Os vários intercursos não adúlteros com mulheres são privados de legitimidade, e são todos reprováveis, e certamente feitos por intemperança. [12.15] Alguém temperante não poderia se rebaixar a relações sexuais com <uma> hetaira, nem com uma mulher livre fora do casamento, nem, pelos Deuses, com uma serva dele, pois o <caráter> ilegítimo e indecente desses intercursos <significa> vergonha e censura aos que os buscam, [12.20] razão pela qual ninguém suporta fazer abertamente essas coisas, mesmo que tenha pouca capacidade de enrubescer. Os que não são completamente dissolutos fazem essas coisas escondidos e em segredo. E certamente, sobre as coisas que alguém faz, tentar passar despercebido é do que admite estar em erro.

[12.25]— Mas, pelos Deuses, diz <alguém>, muito embora o adúltero faça injustiça ao marido da mulher corrompida, o que tem relações com a hetaira não faz injustiça a ninguém, nem, pelos Deuses, <0 que tem relações> com a que não tem marido; pois ele não destrói a esperança de filhos.

Eu, <replicou Musônio>, insisto em dizer que todo aquele que erra e faz injustiça, mesmo se a nenhum dos que são próximos, ele mesmo imediata e absolutamente se mostra pior e mais indigno: pois o que erra, na medida em que erra, é pior e mais indigno. Portanto, aí onde concedo [haver] injustiça, [12.30] é absoluta e totalmente necessário admitir [haver] a intemperança no que é vencido pelo prazer reprovável e no que se deleita em sujar-se, como os porcos: assim como, acima de tudo, é o que tem relações com a própria escrava, coisa que alguns consideram como sendo no mais alto grau isento de culpa, já que também se pensa que o senhor é absolutamente livre para usar o seu escravo como o desejar. Já que também se pensa que o senhor é absolutamente livre para usar o seu escravo como o desejar. [12.35] Quanto a isso para mim o discurso é simples: pois se ao que pensa não ser reprovável nem absurdo o senhor ter relações com a escrava dele, e sobretudo se ocorrer que ela seja solteira ${ }^{14}$, considera o que pareceria a ele, se a senhora tivesse relações com um escravo. Pois não pensaria ser tolerável, não somente se, legalmente casada, a mulher se submetesse a um escravo, [12.40] mas também se, sendo solteira, isso praticasse; certamente, presumo eu, ninguém pensará serem os maridos piores que as mulheres, nem menos capazes de educar os seus próprios apetites, $<$ nem> os mais fortes em conhecimento que os mais fracos, <nem> os que comandam que os comandados. É apropriado que muito melhores sejam os homens, se realmente também [12.45] esperam liderar as mulheres: certamente mostrando-se menos continentes, <mostram-se> também 
piores. É preciso também dizer que é obra da incontinência o senhor ter relações com a escrava? Todos sabem disso ${ }^{15}$.

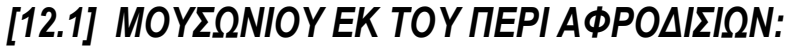

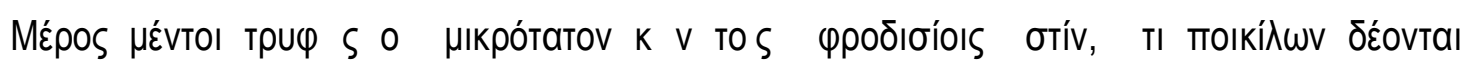

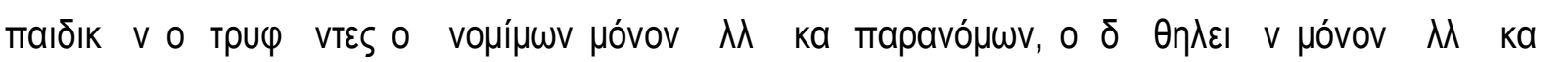

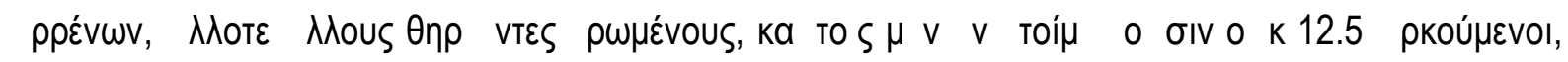

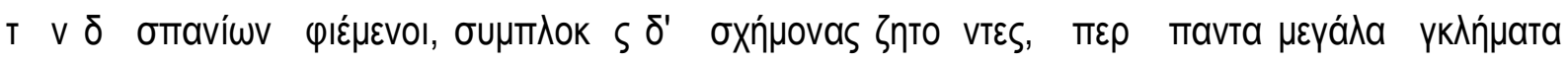

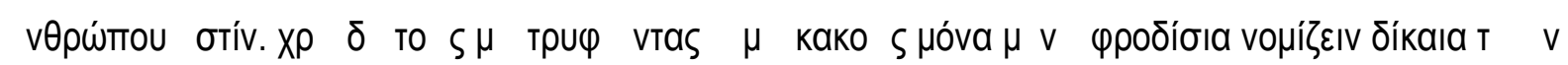

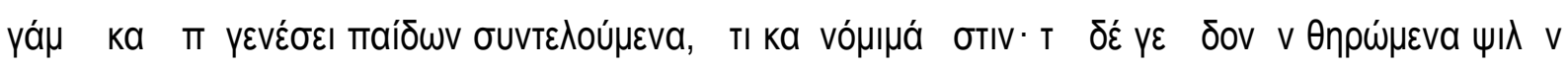

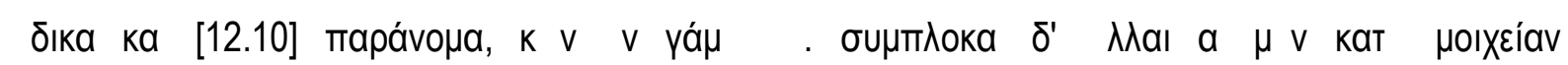

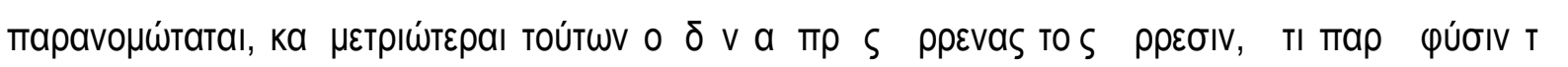

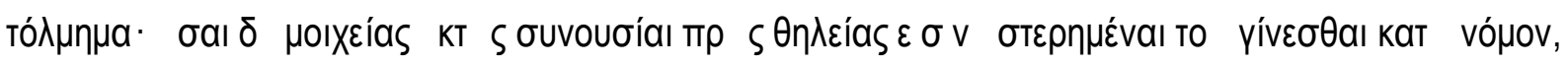

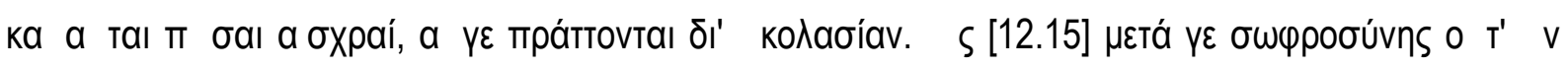

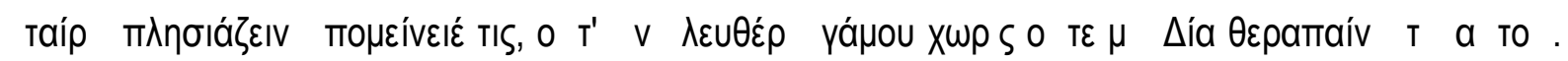

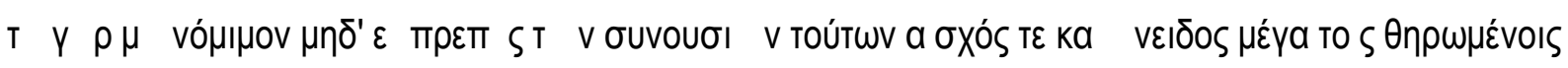

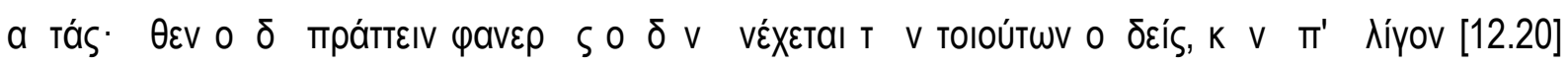

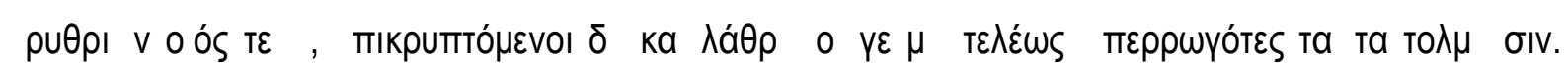

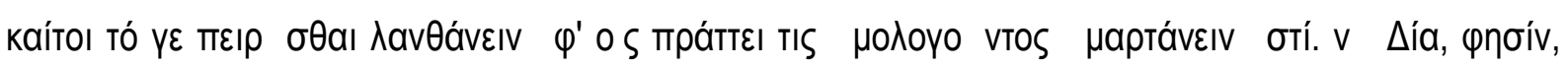

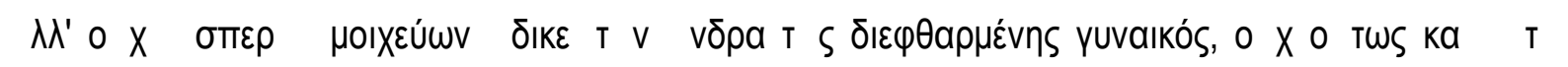

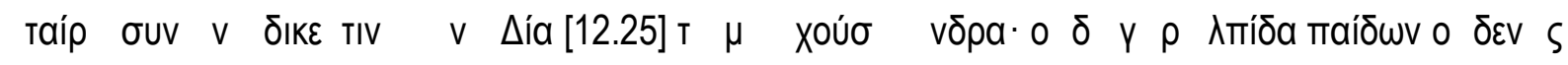

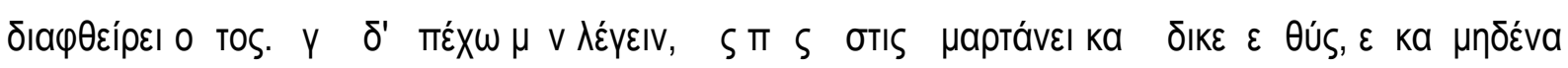

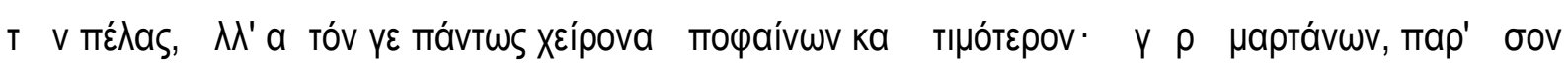

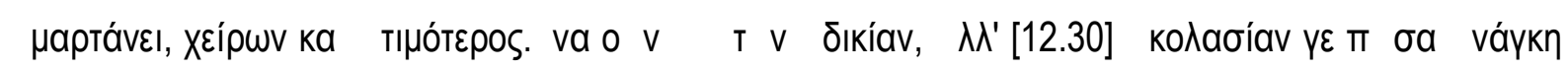

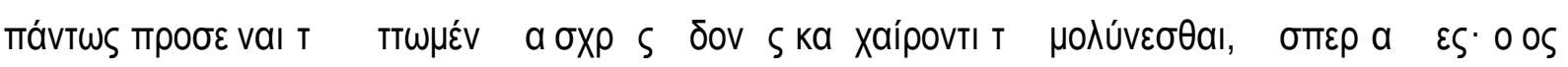

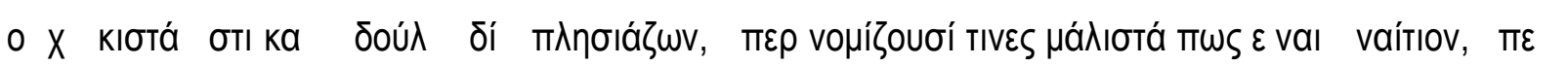

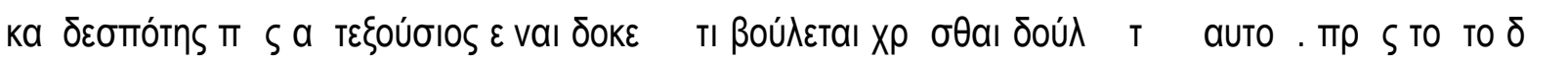




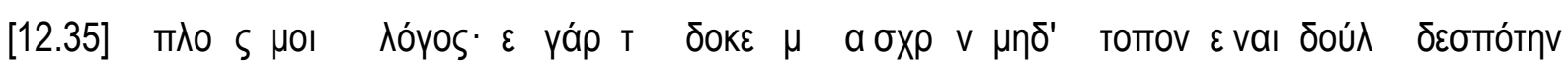

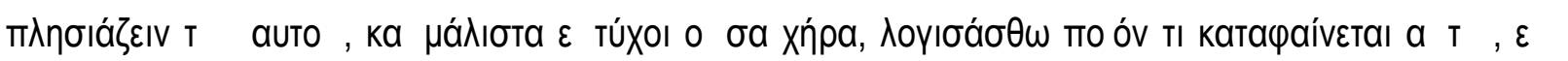

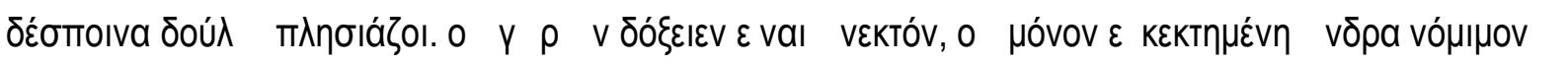

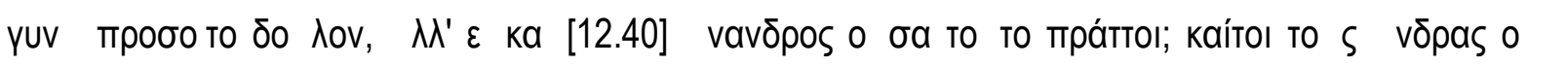

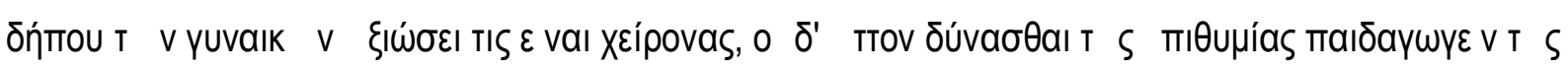

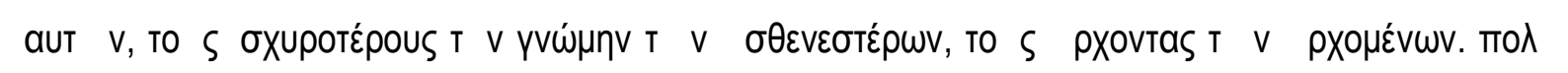

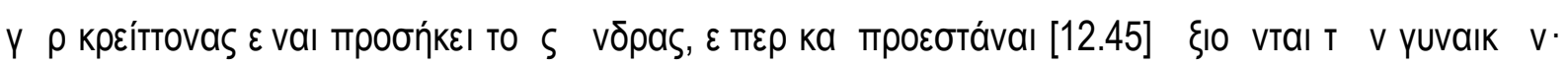

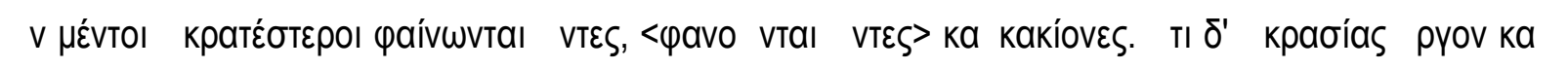

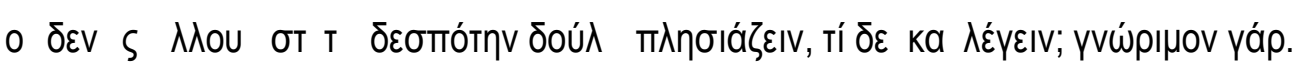

\section{POR MUSÔNIO, DE "O QUE É PRINCIPAL NO CASAMENTO?”}

[13 A.1] O principal no casamento é a comunidade de vida e de criação de filhos. Pois, disse Musônio, é preciso que o marido e a esposa se unam um ao outro por isto: para viverem um com o outro, ter filhos e considerar todas as coisas como comuns [13A.5] e nada como particular, nem o próprio corpo. Com efeito, [é] grande a gênese do homem que o próprio casal produz. Mas isso não basta ao cônjuge, pois que também poderia acontecer de outro modo fora do casamento, do mesmo modo que os animais se unem. Certamente é preciso haver no casamento companheirismo e cuidado mútuo do homem e da mulher, <quando> saudáveis, [13A.10] <quando> doentes, em toda ocasião, cada um desejando <isso> do mesmo modo que desejam ter filhos no casamento. Com efeito, onde o próprio cuidado é completo, e os que convivem fornecem mutuamente por completo esse cuidado, também <os dois> competem em vencer um ao outro <nisso>. Esse casamento, com efeito, é admirável e é digno de elogios; pois bela é tal comunhão. [13A.15] Mas onde um dos dois busca somente o que é seu próprio, descuidando do outro, ou, pelos Deuses, o homem assim é e vive na mesma casa, mas volta a sua atenção para as coisas exteriores, não desejando dedicar-se à esposa, nem consumar a união, aí é necessário ser destruída a comunhão, e mal vão as coisas para os que vivem juntos: ou separam-se por completo [13A.20] ou têm um convívio pior que a solidão.

[13B.1] Ao que se casa, não é necessário considerar a estirpe <do outro> (se <é > de família nobre), nem a riqueza (se possui muitas propriedades), nem o corpo (se o possui belo). Pois nem a 
riqueza, nem a beleza, nem a nobre origem produzem a intensificação da comunhão, como nem a concórdia, nem, novamente, [13B. 5] aperfeiçoa mais a produção de filhos. Mas os corpos que são suficientes para o casamento <são> os saudáveis, de forma proporcional e que se bastam para realizar suas funções. Esses <corpos> têm menor possibilidade de cair em ciladas de licenciosos, são mais capazes de realizar as quantas funções do corpo e podem produzir filhos de modo não deficiente. [13B.10] Deve-se considerar que as almas mais adequadas <para o casamento> são as mais bem dispostas por natureza para a temperança e para a justiça e, em geral, para a excelência. Pois como o casamento <será> bom separado da concórdia? Como a comunhão <será> útil? Como homens maus podem viver em concórdia uns com os outros? Ou como o bom pode viver em concórdia com o mau? Não mais que a um pedaço reto de madeira pode se ajustar a um quebrado, ou que dois quebrados possam se ajustar um ao outro. [13B.15] Pois o quebrado ao quebrado semelhante não se ajusta e ao contrário reto ainda mais. Também o mau não é amigo do mau, nem vive em concórdia <com ele>, nem muito menos com o bom.

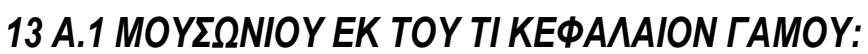

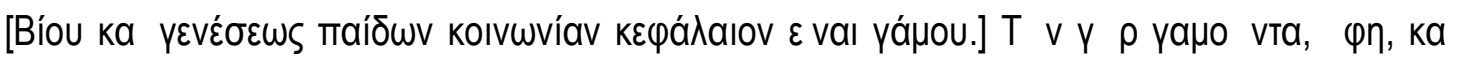

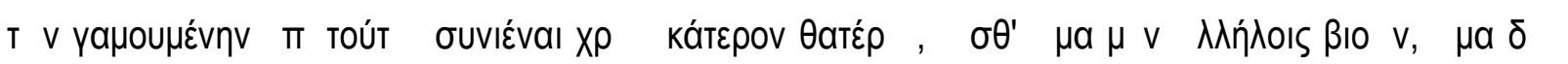

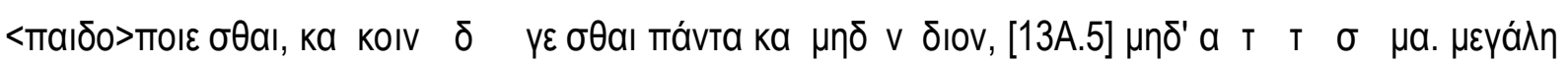

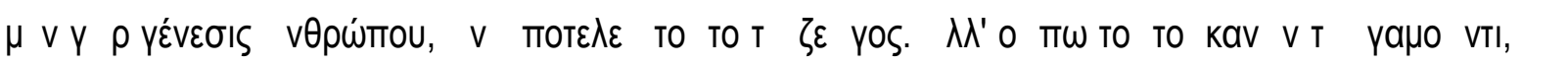

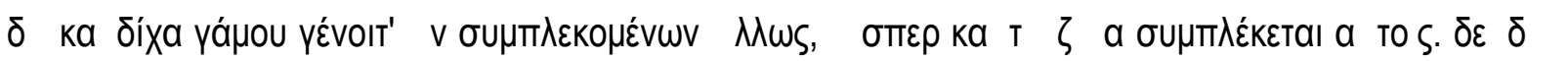

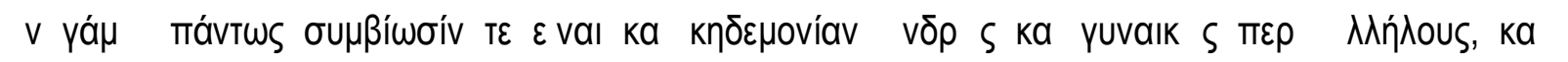

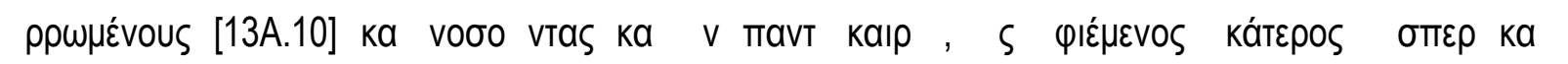
таıठотоі́⿱㇒⿻

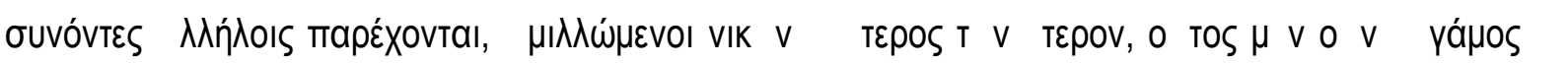

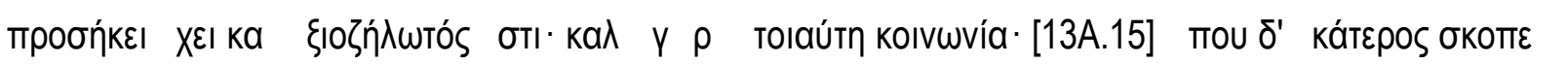

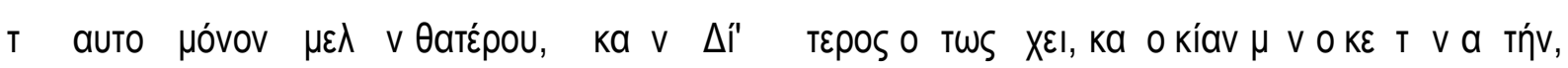

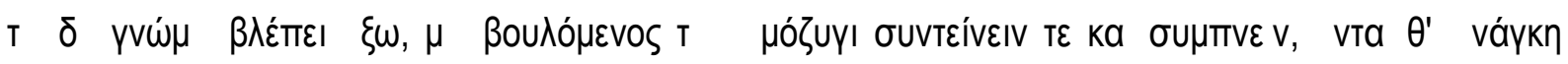

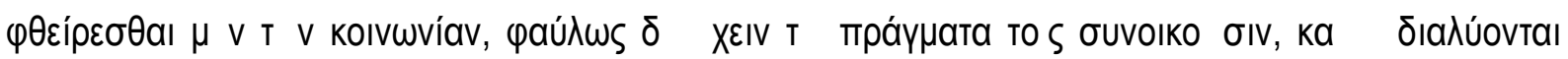

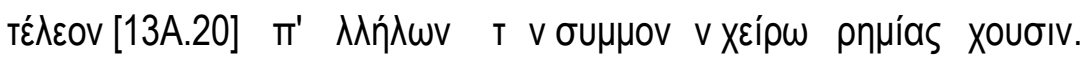




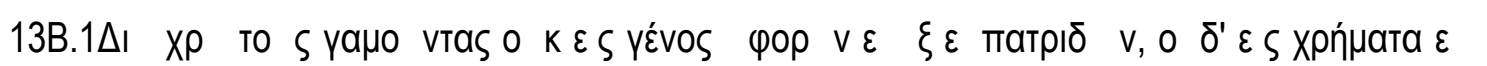

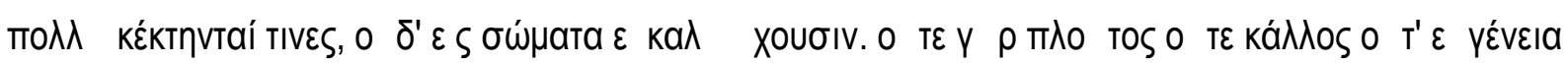

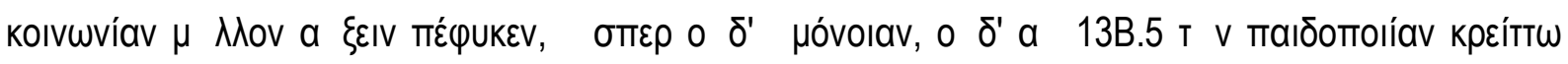

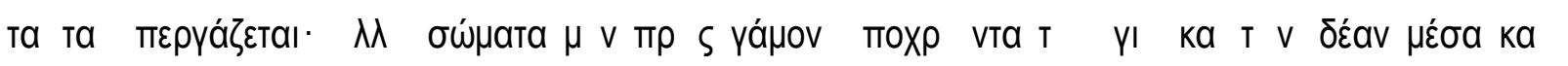

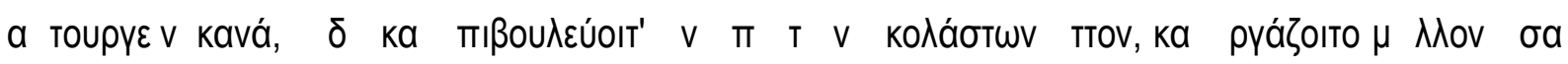

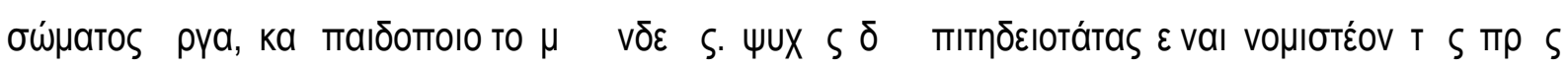

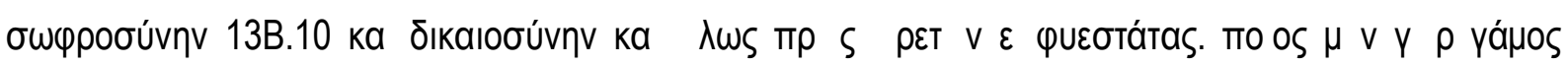

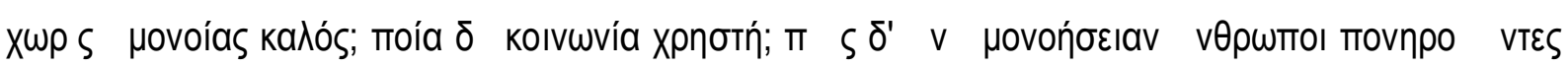

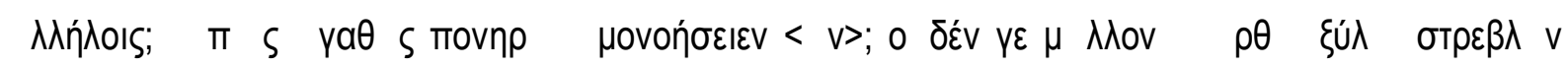

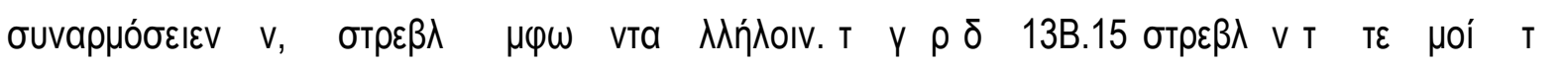

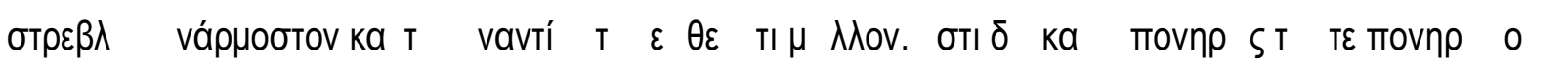

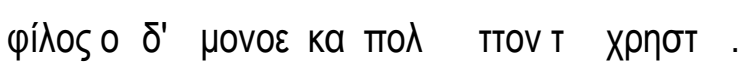

\section{Bibliografia}

AULO GÉLIO. Attic Nights. Volumes I, II, III. Trad. J. C. Rolfe. Harvard: Loeb Classical Library, 1927. DINUCCI, A. Introdução ao Manual de Epicteto. 3 ed. São Cristóvão: EdiUFS, 2012.

DINUCCI, A. Apresentação e Tradução dos Fragmentos Menores de Caio Musônio Rufo. IN: Trans/Form/Ação (UNESP. Marília. Impresso), 2012, v. 35, p. 267- 284.

DION CÁSSIO. Roman History. Trad. Cary; Foster. Harvard: Loeb Classical Library, 1914-1927. EPICTETO. The Discourses as reported by Arrian (Books I, II, III \& IV); Fragments; Encheiridion. Trad. W. A. Oldfather. Cambridge: Loeb, 2000.

EPICTETO. O Encheirídion de Epicteto. Trad. Aldo Dinucci; Alfredo Julien. São Cristóvão: EdiUFS, 2012.

EPICTETO. Testemunhos e Fragmentos. Trad. Aldo Dinucci; Alfredo Julien. São Cristóvão: EdiUFS, 2008.

ESTOBEU. Florilegium, vol I e II. Augustus Meineke (ed.). Lipsiae: Taubner, 1855.

FILOSTRATO. Apollonius of Tiana, Volumes I, II, III. Trad. C. P. Jones. Harvard: Loeb Classical Library, 2005-2006.

FRANCIS, J. A. Subversive virtue: asceticism and authority in the second-century pagan world. University Park, Pa: Pennsylvania State University Press, 1995.

HENSE. Musonii Rufi Reliquiae. Leipzig 1905.

HOMERO. Odisséia. Trad. Antônio Pinto de Carvalho. São Paulo: Abril Cultural, 1981.

JAGU, A. Musonius Rufus. Entretiens et Fragments. Introduction, Traduction et Commentaire. IN: Studien und Materialien zur Geschichte der Philosophie, Kleine Reine, Band I, Olms, 1979.

KING, C. Musonius Rufus: Lectures and Sayings. William B. Irvine (ed.). Seattle: CreateSpace, 2011. LAURENTI. Musonio, maestro di Epitteto. In: Aufstieg und Niedergang der römischen Welt, 2.36.3, 1989, p. 2105-2146.

LUTZ, C. Musonius Rufus: The Roman Socrates. IN: Yale Classical Studies, Volume X. A. R. Bellinger (ed.). Yale: Yale University Press, 1947.

PLÍNIO, O JOVEM. Letters, Volumes I, II. Trad. B. Radice. Harvard: Loeb Classical Library, 1969.

PLUTARCO. On the Control of Anger. Trad. W. C. Helmbold. Harvard: Loeb Classical Library, 1939. 
QUINTILIANO. The Orator's Education, VolumeS I, II, III, IV, V. Trad. D. A. Russel. Harvard: Loeb Classical Library, 2002.

SCHENKL H. Die Epiktetishen Fragmente. In: Sitzungsberichte der philos. - hist. Calsse der K. Akad. der Wiss. Viena, 115 (1888), 443-546.

SUIDAS. Suidae lexicon. Ada Adler (ed.). Leipzig: 1928-1938.

TÁCITO. Annals, Volumes I, II. Trad. Jackson John. Harvard: Loeb Classical Library, 1937.

TÁCITO. Histories, Volumes I, II. Trad. Clifford, M; J. Jackson. Harvard: Loeb Classical Library, 19251931. 